\title{
RANCANG BANGUN ROBOT LENGAN DENGAN PENGGERAK SISTEM PNEUMATIK MENGGUNAKAN PLC
}

\author{
Supriyono $^{1}$, Muhamad Yusuf ${ }^{2}$, Arif Ainur Rafiq ${ }^{3}$ \\ 1,2,3 Jurusan Teknik Elektronika Politeknik Negeri Cilacap \\ Email : supriyono3008@gmail.com, muhamad.yusuf.1986@gmail.com, arifainurrafiq@gmail.com
}

\begin{abstract}
Utilizing of robots is increasing every year, especially in the industrial field. Robotic arm is one type of robot that used in industry. This robotic arm system is used to move an object from one point to another using a gripper. In this research, the pneumatic system is used as the actuator of the robotic arm (manipulator) and Programmable Logic Controller (PLC)is usedas the controller. The results of this prototype research isa robotic arm that can move object from one point to another point that has been determined. Timing diagrams are used to describe the movement of each arm on the robot. From the experimental results of the overall system, the average time of the robotic arm to move one object in one cycle movement is 18.46 seconds, with a settling time of one cycle is 18 seconds.
\end{abstract}

Keywords: Programmable Logic Controller, pneumatic, robot arm

\section{INTISARI}

Penggunaan robot setiap tahun terus meningkat, terutama di bidang industri. Lengan robot/arm robot merupakan salah satu jenis robot yang digunakan di bidang industri. Sistem lengan robot ini digunakan untuk memindahkan suatu benda dari suatu titik ke titik yang lain menggunakan gripper. Pada penelitian ini sistem pneumatik digunakan sebagai penggerak lengan robot (manipulator) dan sebagai pengendalinya digunakan Programmable Logic Controller (PLC). Hasil penelitian rancang bangun ini berupa produk robot lengan yang dapat memindahkan objek/benda dari satu titik ke titik yang lainnya yang sudah ditentukan. Timing diagram digunakan untuk menggambarkan pergerakan masing-masing lengan pada robot. Dari hasil pengujian sistem secara keseluruhan waktu rata-rata lengan robot memindahkan satu benda dalam satu siklus gerakan yaitu sebesar 18,46 detik, dengan set waktu satu siklus sebesar 18 detik.

Kata Kunci : Programmable Logic Controller, pneumatic, robot lengan

\section{PENDAHULUAN}

Penggunaan robot setiap tahun terus meningkat, hal ini dibuktikan dengan kenaikan penjualan robot sebesar $12 \%$ pada tahun 2013, yaitu sebanyak 178.132 unit [4]. Melihat pesatnya penggunaan robot di dunia, terutama dibidang industri, maka dalam penelitian ini diteliti dan dibahas mengenai lengan robot dalam skala kecil atau laboratorium. Lengan robot ini berfungsi untuk memindahkan suatu beban benda dengan massa tertentu dari satu titik ke titik yang lain, yang sudah ditentukan sebelumnya. Sistem pneumatik digunakan sebagai penggerak lengan robot (manipulator) dan sebagai pengendalinya digunakan Programmable Logic Controller (PLC). Penggunaan PLC sebagai pengendali lengan robot dikarenakan PLC mempunyai beberapa keunggulan dibandingkan jenis pengendali yang lain, antara lain; mudah dalam melakukan instalasi, mudah dalam pengembangan dan modifikasi sistem, mudah dalam melakukan pemrograman, terdapat fungsi diagnostik dalam PLC sehingga mudah dan cepat dalam pendeteksian kesalahan, serta mudah dalam merubah urutan proses atau operasional sistem. Sistem pneumatik dipilih sebagai penggerak lengan robot karena skala robot yang dirancang merupakan skala kecil dari robot industri jadi membutuhkan gaya yang relatif kecil untuk memindahkan benda atau objek. Penggunaan tekanan udara dalam sistem pneumatik juga lebih murah karena udara diperoleh secara bebas dan lebih bersih daripada sistem hidrolik yang menggunakan cairan (minyak/oli). 


\section{METODE PENELITIAN}

\section{A. Desain Mekanik Lengan Robot}

Lengan robot yang dibuat mempunyai jangkauan maksimal sebesar $32 \mathrm{~cm}$ dan sudut pemindahan benda sebesar $30^{\circ}$ diukur dari pangkal lengan robot. Robot lengan terdiri dari 3 lengan (link) dengan ukuran panjang lengan 1 sebesar $22 \mathrm{~cm}$, lengan 2 sebesar $37,5 \mathrm{~cm}$ dan lengan 3 termasuk gripper pada ujung lengan 3 sebesar $30 \mathrm{~cm}$.

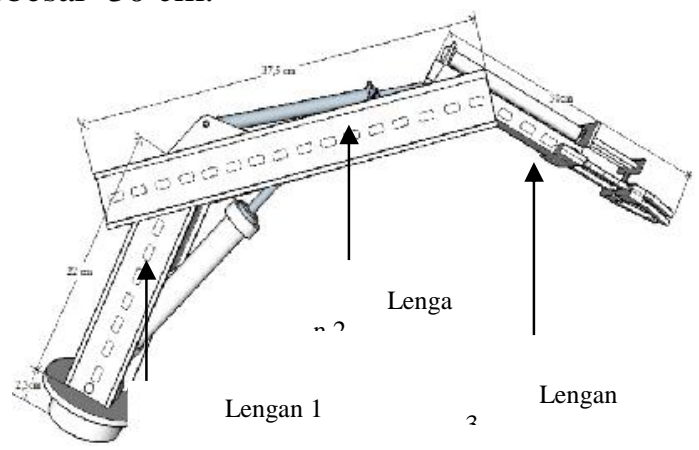

Gambar 1. Rancangan Mekanik Lengan Robot

Robot lengan ini menggunakan 4 cyilinder pneumatik sebagai penggerak lengan-lengan robot dan gripper untuk mencengkram benda yang akan dipindahkan. Cylinder 1 digunakan untuk gripper, cylinder 2 untuk lengan ketiga, cylinder 3 untuk penggerak lengan kedua dan cylinder 4 untuk pemutar pada sumbu robot. Cylinder pneumatik ini digerakan menggunakan control valve, yang dikendalikan oleh PLC yang telah terprogram. Empat cylinder pneumatik yang digunakan merupakan cylinder pneumatik jenis double acting cylinder. Valve pneumatik yang digunakan adalah valve jenis $5 / 2$. Sebagai sumber udara kempa atau udara bertekanan digunakan kompresor.

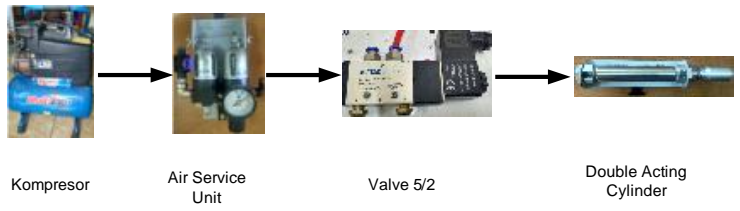

Gambar 2. Diagram Blok Sistem Pneumatik Penggerak Lengan Robot

\section{B. Rancang Bangun Sistem Lengan Robot}

Sebagai pendeteksi benda yang akan dipindahkan digunakan sensor proximity induktif, sensor ini akan mendeteksi benda dari bahan logam. Sensor proximity yang digunakan sebanyak dua buah, satu sensor mendeteksi benda pada titik A (titik awal benda), dan yang satunya mendeteksi benda pada titik B (titik akhir benda).

Blok diagram dari sistem lengan robot dapat dilihat pada Gambar 3.

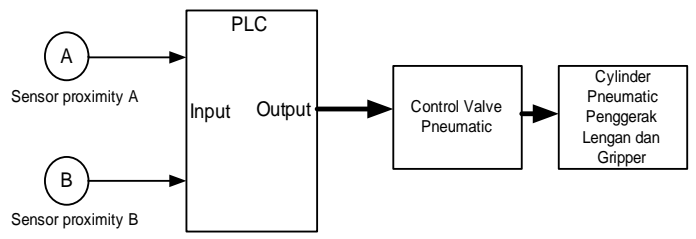

Gambar 3. Blok Diagram Sistem Lengan Robot

Benda pada titik A dideteksi oleh sensor proximity kemudian sensor mengirim hasilnya ke input PLC, begitu juga dengan sensor proximity pada titik B. Jika terdapat benda pada titik A dan tidak ada benda pada titik B, maka PLC akan mengendalikan lengan robot untuk memindahkan benda dari titik A ke titik B, tetapi jika sudah ada benda pada titik B maka lengan robot tidak akan memindahkan benda yang ada pada titik A. Diagram alir sistem lengan robot dapat dilihat pada Gambar 4.

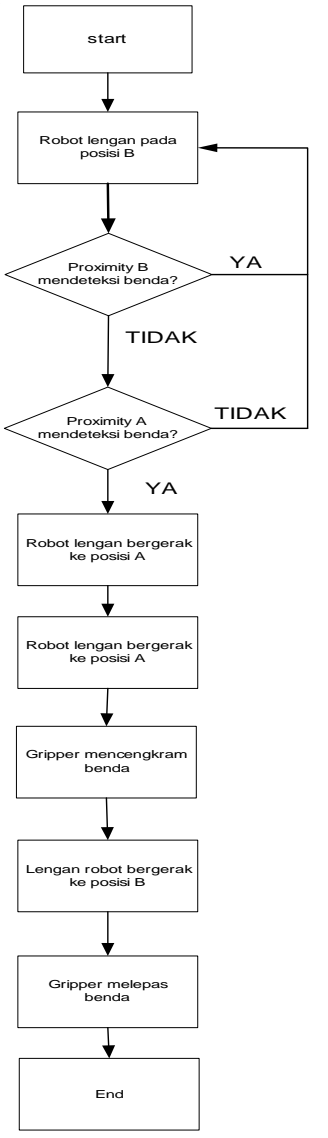

Gambar 4. Diagram Alir Sistem Lengan Robot 
Sistem lengan robot ini menggunakan PLCC Omron tipe CP1E E20 sebagai pengendali gerakan lengan. Alamat input dan output PLC yang dipakai untuk sistem lengan robot dapat dilihat pada Tabel 1.

Tabel 1. Pengalamatan I/O pada PLC

\begin{tabular}{|c|c|c|c|}
\hline No. & Alamat & Jenis & Keterangan \\
\hline 1. & 0.00 & Input & Sensor proximity A \\
\hline 2. & 0.01 & Input & Sensor proximity B \\
\hline 3. & 0.02 & Input & Tombol start \\
\hline 4. & 0.03 & Input & Tombol stop \\
\hline 5. & 100.00 & Output & Valve 2 (C2)/Lengan 2 \\
\hline 6. & 100.01 & Output & Valve 1 (C1)/Gripper \\
\hline 7. & 100.02 & Output & Valve 3 (C3)/Lengan 3 \\
\hline 8. & 100.03 & Output & $\begin{array}{c}\text { Valve 4 (C4)/Pemutar } \\
\text { lengan }\end{array}$ \\
\hline
\end{tabular}

Waktu setiap satu siklus gerakan lengan robot dalam memindahkan benda dari titik A ke titik B dirancang sebesar 18 detik. Timing diagram digunakan untuk menggambarkan urutan waktu pergerakan setiap bagian atau lengan pada saat proses pemindahan benda. Gambar 5 merupakan timing diagram gerakan lengan robot dalam memindahkan benda.

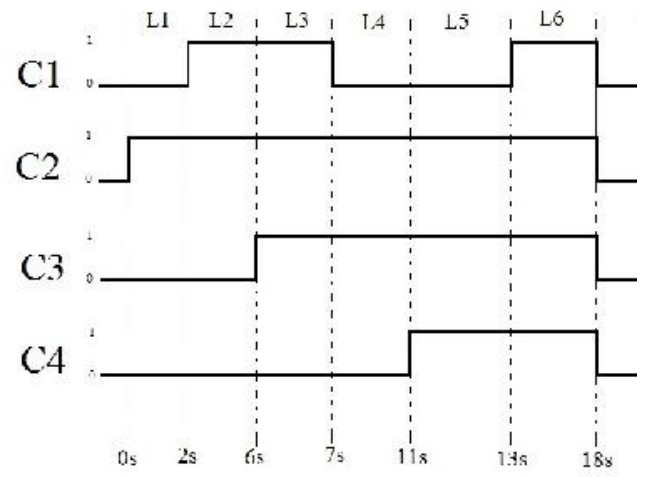

Gambar 5. Timing Diagram Gerakan Lengan Robot

C1 merupakan pergerakan gripper dimana logic 1 adalah saat gripper mencengkram dan logic 0 adalah saat gripper membuka. C2 merupakan cylinder penggerak lengan kedua. C3 adalah cylinder penggerak lengan ketiga dan yang terakhir $\mathrm{C} 4$ merupakan cylinder pemutar lengan robot. Bentuk lengan robot ini dapat dilihat pada Gambar 5.

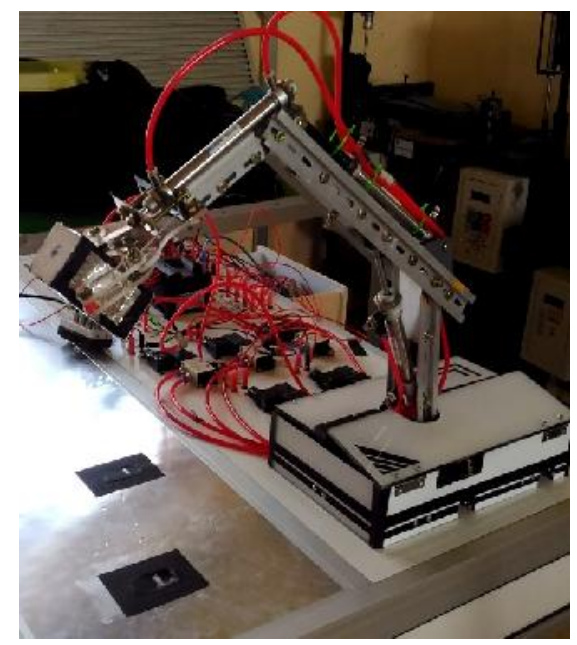

Gambar 5. Lengan Robot

\section{HASIL DAN PEMBAHASAN}

Uji coba tekanan udara optimal pada cylinder pneumatik pada penggerak lengan robot dilakukan dengan memberikan tekanan udara yang bervariasi pada masing-masing cylinder (C1, C2, C3 dan C4). Uji coba dilakukan tanpa memberi beban benda pada lengan robot. Tekanan yang diberikan ke cylinder bervariasi dari 0 bar sampai dengan 4 bar. Berikut adalah hasil uji coba pada cylinder pneumatik pada lengan robot.

Tabel 2. Hasil uji coba tekanan pada cylinder pneumatik

\begin{tabular}{|c|c|c|c|c|c|}
\hline No. & $\begin{array}{c}\text { Tekanan udara } \\
\text { (bar) }\end{array}$ & C1 & C2 & C3 & C4 \\
\hline 1. & 0 & - & - & - & - \\
\hline 2. & 0,5 & - & - & - & - \\
\hline 3. & 1 & - & - & - & - \\
\hline 4. & 1,5 & $\checkmark$ & $\checkmark$ & $\checkmark$ & $\checkmark$ \\
\hline 5. & 2 & $\checkmark$ & $\checkmark$ & $\checkmark$ & $\checkmark$ \\
\hline 6. & 2,5 & $\checkmark$ & $\checkmark$ & $\checkmark$ & $\checkmark$ \\
\hline 7. & 3 & $\checkmark$ & $\checkmark$ & $\checkmark$ & $\checkmark$ \\
\hline 8. & 3,5 & $\checkmark$ & $\checkmark$ & $\checkmark$ & $\checkmark$ \\
\hline 9. & 4 & $\checkmark$ & $\checkmark$ & $\checkmark$ & $\checkmark$ \\
\hline
\end{tabular}

Pada Tabel 2 terlihat bahwa semua cylinder pneumatik penggerak lengan robot mulai bekerja jika diberi udara bertekanan 1,5 bar.

Uji coba kinerja lengan robot merupakan uji coba keseluruhan kinerja lengan robot dalam memindahkan benda dari titik A ke titik B. Hasil yang diharapkan adalah kinerja lengan robot bisa 9 
memindahkan benda secara kontinyu dan konsisten terutama dari performa waktu. Waktu yang di set untuk satu kali proses pemindahan benda adalah 18 detik. Tekanan udara yang digunakan pada uji coba ini sebesar 3 bar. Berikut ini adalah hasil uji coba lengan robot dalam memindahkan benda.

Tabel 3. Hasil uji coba waktu pemindahan benda kerja oleh lengan robot.

\begin{tabular}{|c|c|c|c|}
\hline No. & $\begin{array}{c}\text { Setting waktu } \\
\text { (detik) }\end{array}$ & $\begin{array}{c}\text { Waktu } \\
(\text { detik })\end{array}$ & $\begin{array}{c}\text { Simpangan } \\
\text { (detik) }\end{array}$ \\
\hline 1. & 18 & 18,52 & 0,52 \\
\hline 2. & 18 & 18,55 & 0,55 \\
\hline 3. & 18 & 18,28 & 0,28 \\
\hline 4. & 18 & 18,63 & 0,63 \\
\hline 5. & 18 & 18,50 & 0,50 \\
\hline 6. & 18 & 18,43 & 0,43 \\
\hline 7. & 18 & 18,10 & 0,10 \\
\hline 8. & 18 & 18,34 & 0,34 \\
\hline 9. & 18 & 18,88 & 0,88 \\
\hline 10. & 18 & 18,47 & 0,47 \\
\hline
\end{tabular}

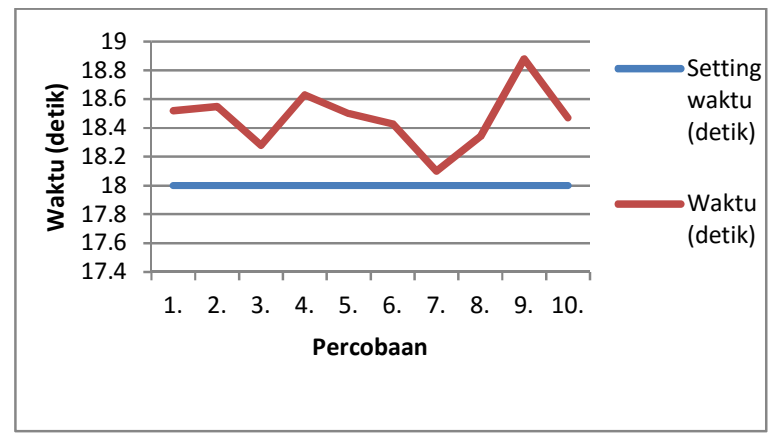

Gambar 7. Hasil uji coba lengan robot

Dari Tabel 3 terlihat bahwa dari set waktu awal sebesar 18 detik untuk sekali proses pemindahan benda, dalam uji coba ini rata-rata waktu pemindahan sebesar 18,47 detik.

\section{KESIMPULAN}

Berdasarkan hasil uji coba sistem lengan robot dengan sistem pneumatik sebagai penggerak lengan didapat kesimpulan sebagai berikut:

1. Tekanan udara yang digunakan untuk menggerakan lengan robot minimal sebesar 1,5 bar.

2. Sistem lengan robot dengan PLC sebagai pengendali dapat memindahkan benda dari titik A ke titik B dengan waktu rata-rata sebesar 18,47 detik untuk seting waktu 18 detik, pada tekanan udara 3 bar.

\section{DAFTAR PUSTAKA}

[1]. Bimantaka, Bryan Novega Whildan, dkk..2014. Purwarupa Robot Lengan Pemilah Objek Berdasarkan Label Tulisan Secara Realtime . Universitas Gadjah Mada. Yogyakarta.

[2]. Bolton, William. 2004. Programmable Logic Controller (PLC) Edisi 3. Erlangga. Jakarta.

[3]. Firmasyah, dkk. 2014. Perancangan Lengan Robot 5 Derajat Kebebasan dengan Pendekatan Kinematika. Universitas Syiah Kuala, Banda Aceh.

[4]. IFR Statistical Department, "Executive summary World Robotics 2014 Industrial Robots," world robotic, pp11,24. 2014.

[5]. Moh. Khairudin, dkk.2013. Pengembangan Unit Robot Lengan Lentur Dua-Link Sebagai Sarana Pengembangan Kompetensi Bidang Otomasi Dan Robotika Guru-Guru Smk Jurusan Listrik Dan Elektronika. Universitas Negeri Yogyakarta. Yogyakarta.

[6]. Parr, Andrew. 2003. Hidrolika dan Pneumatika: Pedoman Bagi Teknisi dan Insinyur. Erlangga. Jakarta.

[7]. Suyadi, Sunarto. 2012. Lengan Robot Sistem Pneumatik Untuk Alat Pembelajaran Aplikasi Mikrokontroler. Politeknik Negeri Semarang. Semarang. 